\title{
¿Identidad étnica, hegemonía o resistencia? El antifascismo italiano y el monumento a Giuseppe Garibaldi (Bahía Blanca, Argentina, 1927-1928)
}

\section{Bruno Cimatti}

Universidad Nacional del Sur (UNS)-CONICET. Centro de Estudios Regionales Prof. Félix Weinberg. Departamento de Humanidades bruno.cimatti@uns.edu.ar

\section{Resumen}

El artículo aborda las relaciones entre espacio, política e identidad étnica en función de los sentidos atribuidos al monumento a Giuseppe Garibaldi de Bahía Blanca (Provincia de Buenos Aires, Argentina) por parte del antifascismo local. En particular, nos centramos en el proceso que condujo a su construcción, para lo que se ha estudiado la prensa local, así como la documentación disponible en el archivo de la Sociedad Italiana de Socorros Mutuos de Bahía Blanca. Interpretamos que el monumento representó a la vez una reivindicación identitaria, una demostración de hegemonía y una manifestación de resistencia. En general, nuestro aporte busca contribuir al campo de estudio de los monumentos como formas simbólicas espaciales de la política, mediante el análisis de un caso que pone en juego las nociones de identidad y poder en función de la localización, las dimensiones y las prácticas articuladas en torno al monumento a Garibaldi.

Palabras clave: antifascismo; formas simbólicas espaciales; monumentos; identidad; poder

Resum. Identitat ètnica, hegemonia o resistència? L'antifeixisme italià $i$ el monument a Giuseppe Garibaldi (Bahia Blanca, Argentina, 1927-1928)

Aquest article s'ocupa de les relacions entre espai, política i identitat ètnica en funció dels sentits atribuïts al monument a Giuseppe Garibaldi de Bahía Blanca (Província de Buenos Aires, Argentina) per part de l'antifeixisme local. En particular, ens centrem en el procés de la seva construcció, i per fer-ho s'ha estudiat la premsa local, així com la documentació disponible a l'arxiu de la Sociedad Italiana de Socorros Mutuos de Bahía Blanca. Interpretem que el monument representa alhora una reivindicació identitària, una demostració d'hegemonia i una manifestació de resistència. En general, el nostre treball pretén contribuir al camp d'estudi dels monuments com a formes simbòliques espacials de la política, mitjançant l'anàlisi d'un cas que posa en joc les nocions d'identitat i poder, en funció de la localització, les dimensions i les pràctiques articulades al voltant del monument a Garibaldi. Paraules clau: antifeixisme; formes simbòliques espacials; monuments; identitat; política 
Résumé. Identité ethnique, hégémonie ou résistance ? L'antifascisme italien et le monument à Giuseppe Garibaldi (Bahía Blanca, Argentine, 1927-1928)

Cet article traite des relations entre espace, politique et identité ethnique en fonction des sens attribués au monument à Giuseppe Garibaldi de Bahía Blanca (Province de Buenos Aires, Argentine) de la part de l'antifascisme local. En particulier, nous nous centrons sur le processus de sa construction, à partir de l'étude de la presse locale ainsi que de la documentation disponible dans les archives de la Sociedad Italiana de Socorros Mutuos de Bahía Blanca. Nous interprétons que le monument a représenté à la fois une revendication d'identité, une démonstration d'hégémonie et une manifestation de résistance. En général, ce travail cherche à apporter une contribution au domaine d'études des monuments en tant que formes symboliques spatiales de la politique à travers l'analyse d'un cas dans lequel les notions d'identité et de pouvoir entrent en jeu selon l'emplacement, les dimensions et les pratiques qui s'articulent autour du monument à Garibaldi.

Mots-clés: antifascisme; formes symboliques spatiales; monuments; identité; politique

Abstract. Ethnic identity, hegemony or resistance? Italian antifascism and the Giuseppe Garibaldi Memorial (Bahia Blanca, Argentina, 1927-1928)

This article addresses the relationships between space, politics and ethnic identity based on the meanings given to the Giuseppe Garibaldi Memorial in Bahía Blanca (Buenos Aires Province, Argentina) by the local antifascism movement. Particularly, we focus on the process that led to the memorial's construction. To this end, we studied the local press, as well as documents housed in the archive of the Sociedad de Socorros Mutuos de Bahía Blanca. We observe that the monument represented at the same time an identity claim, a demonstration of hegemony and a manifestation of resistance. Our general aim is to contribute to the field of monument analysis as symbolic spatial forms of politics through the study of a case that brings into play notions of identity and power in relation to localization, dimensions and practices developed around the Garibaldi Memorial.

Keywords: antifascism; symbolic spatial forms; monuments; identity; politics

\section{Sumario}

1. Introducción 4. Los italianos de Bahía Blanca ante

2. Los monumentos como formas el advenimiento del fascismo simbólicas espaciales de la política

3. Un héroe nacional en disputa: 5. Los antifascistas bahienses y el monumento a Garibaldi la figura de Garibaldi entre el fascismo 6. Consideraciones finales y el antifascismo

Referencias bibliográficas

\section{Introducción}

El presente trabajo busca abordar las relaciones entre espacio, política e identidad étnica en función de los sentidos que el antifascismo atribuyó al monumento a Giuseppe Garibaldi de Bahía Blanca, ciudad cabecera del partido homónimo situada en el sudoeste de la Provincia de Buenos Aires (República 
Figura 1. Bahía Blanca en 1928

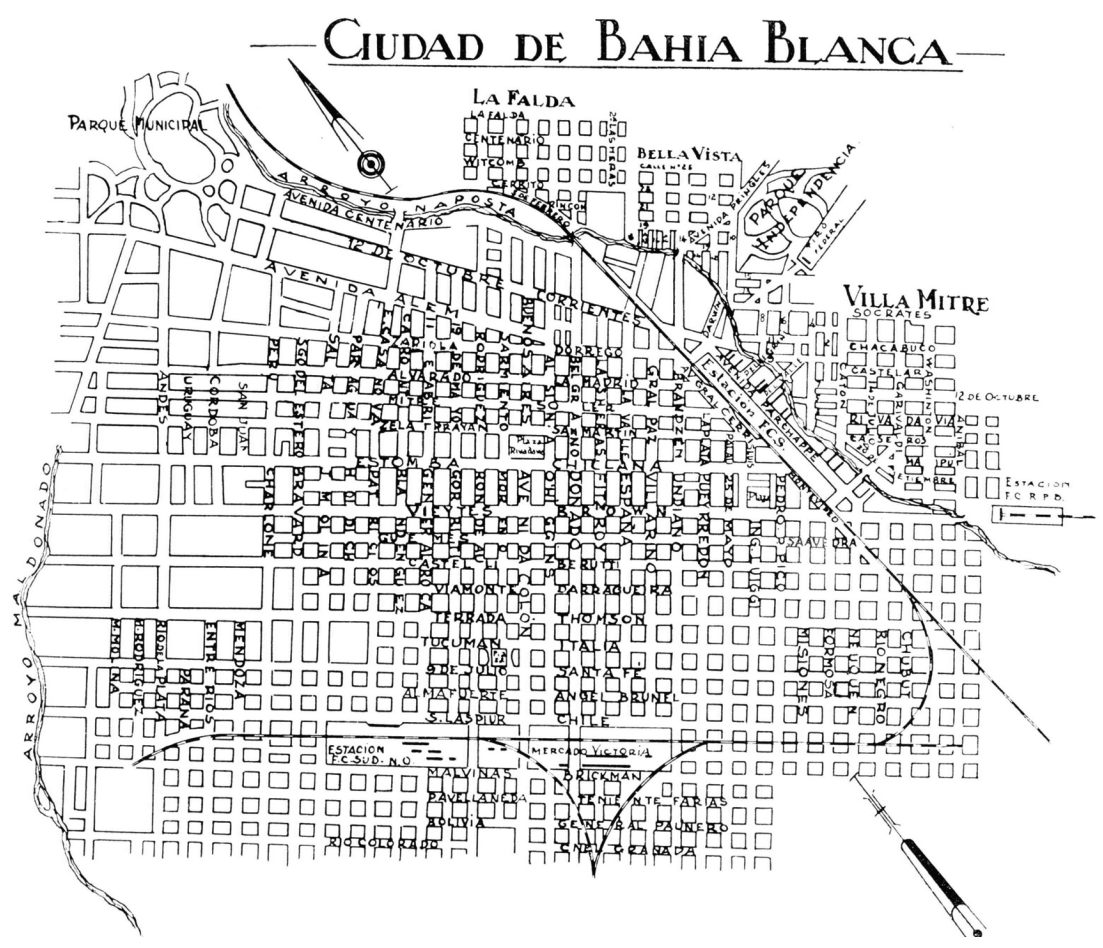

Fuente: Cernadas y Marcilese (2017: 42).

Argentina) (figura 1) ${ }^{1}$. Para ello, nos centraremos en el análisis del proceso de construcción del monumento, que fue un obsequio de la colectividad italiana a la ciudad durante los festejos del centenario de la ciudad (celebrado el $11 \mathrm{de}$ abril de 1928) ${ }^{2}$.

El trabajo ha sido realizado desde una perspectiva centrada en la espacialidad, tanto material como simbólica, de la forma monumental inaugurada en 1928 (figura 2). El monumento se constituyó desde entonces en un punto de referencia ineludible para el movimiento antifascista bahiense, primero, y con

1. Deseamos realizar un agradecimiento al Dr. Fabián Claudio Flores (Universidad Nacional Luján-CONICET) por sus sugerencias para la elaboración del presente artículo, así como al Dr. Rodrigo Vecchi (Universidad Nacional del Sur-CONICET) por su colaboración y su trabajo pionero sobre la problemática que aquí tratamos (Vecchi, 2003).

2. La fecha reconocida como el origen de Bahía Blanca es el 11 de abril de 1828, año de fundación de la Fortaleza Protectora Argentina. Sin embargo, el origen de la ciudad como tal es más tardío, y solo alcanzó proyecciones importantes tras la llegada del ferrocarril y la inauguración del puerto en la década de 1880 (Cernadas et al., 2016: 15-22). 
Figura 2. Inauguración del monumento a Garibaldi, 11 de abril de 1928

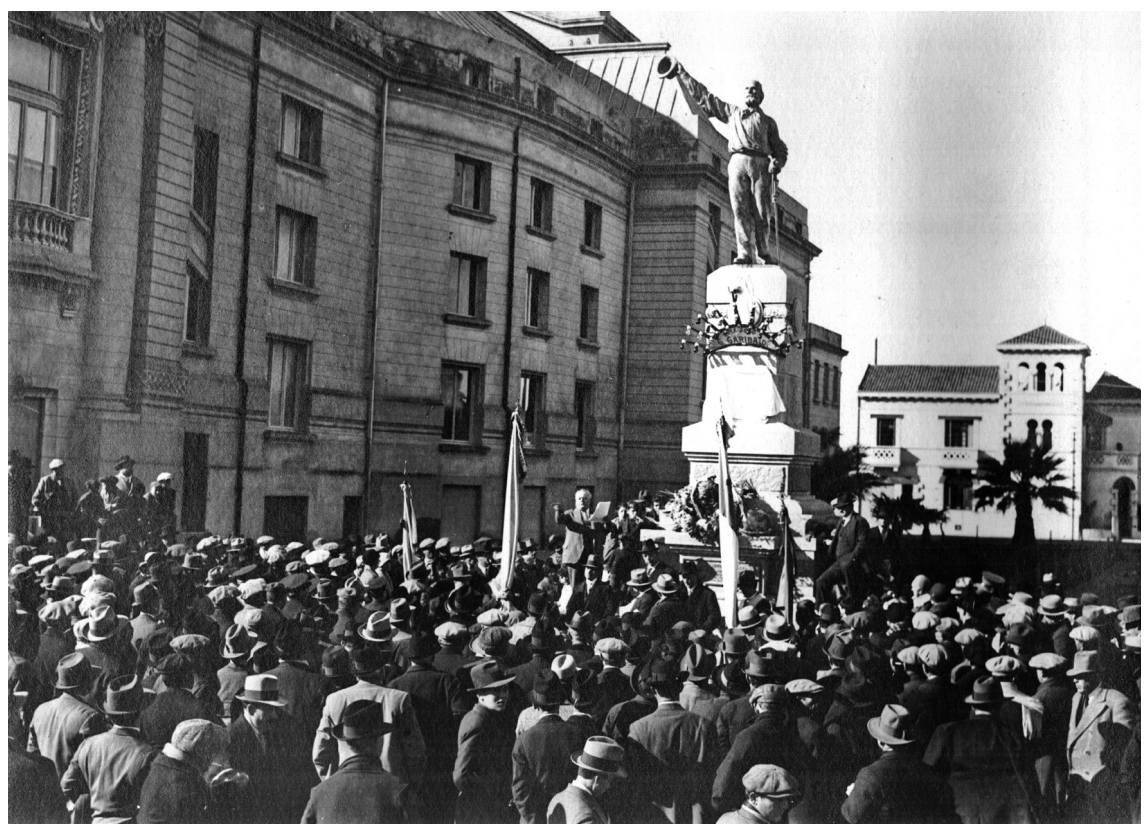

Fuente: disponible en la Sociedad Italiana de Socorros Mutuos de Bahía Blanca y en el Archivo de la Memoria de la Universidad Nacional del Sur (Bahía Blanca, Argentina).

el correr del tiempo para la colectividad en general, por lo que su representatividad ideológica le otorgó una trascendencia que excedió el plano de sus dimensiones espaciales materiales.

Nuestra investigación se reconoce deudora de un primer acercamiento realizado por Rodrigo Vecchi $(2003)^{3}$, quien analizó la disputa política en torno al monumento desde una perspectiva centrada en las dimensiones políticas del arte. Nuestro análisis buscará profundizar los alcances de ese estudio pionero a partir de la utilización de conceptos y enfoques teóricos propios de las geografías culturales, particularmente en relación con los monumentos como formas simbólicas espaciales.

El trabajo se divide en cuatro apartados. En el primero, se presenta una revisión de diversos estudios sobre los monumentos y su vinculación con la política realizados desde una perspectiva geográfica, los cuales aportan el marco teórico en que anclamos nuestro trabajo. El segundo apartado se ocupa de las disputas que tuvieron lugar en Italia entre fascistas y antifascistas por la

3. Si bien la ponencia presentada por Vecchi en el II Congreso Internacional de Teoría e Historia de las Artes y X Jornadas CAIA no está publicada, una versión resumida de la misma puede encontrarse en Ribas y Tolcachier (2012: 61-67). 
apropiación del legado de Garibaldi, así como del especial significado que su figura adoptó entre los inmigrantes italianos en Sudamérica, y particularmente en Argentina. El tercer apartado presenta una descripción de la relevancia de la colectividad migratoria italiana que se asentó en Argentina (y puntualmente en Bahía Blanca) entre fines del siglo xix y principios del xx, así como del proceso que la misma atravesó como resultado del surgimiento y la llegada al poder del fascismo en Italia. Finalmente, el cuarto apartado se centra en los significados adoptados por el monumento a Garibaldi en función de la disputa que los antifascistas locales entablaron con sus adversarios fascistas en tiempos del centenario de la ciudad.

La investigación realizada se basó tanto en fuentes periodísticas bahienses como en la documentación disponible en el archivo de la Sociedad Italiana de Socorros Mutuos de Bahía Blanca. Entre las primeras, destacan La Nueva Provincia, principal diario de la ciudad tanto por su nivel de tirada como por el volumen de cada edición, y el periódico Nuevos Tiempos, órgano de prensa del Centro Socialista local ${ }^{4}$. En cuanto a los archivos societarios mencionados, se analizaron libros de actas del Consejo Directivo y libros de asambleas 5 .

El análisis desarrollado representa un acercamiento desde la disciplina histórica hacia las geografías culturales y busca nutrirse de los enfoques que desde esta última se han dedicado a indagar las formas simbólicas espaciales de la política y, en particular, el estudio de los monumentos como transmisores de significados atravesados por cuestiones de identidad y poder. La construcción del monumento revela entonces su indudable carácter político, al presentarse como parte del "proceso siempre conflictivo de elaboración de las reglas explícitas o implícitas de lo participable y lo compartible» en el conjunto social (Rosanvallon, 2003: 16). Puede considerarse, por lo tanto, que la hegemonía sobre la colectividad italiana constituyó un elemento a disputar en el espacio público, comprendido como «un campo abierto a la transformación de las relaciones de poder que lo constituyen, evidenciándose no solo como el escenario en el que se despliega la praxis, sino como el mismo objetivo de esta» (Velázquez Ramírez, 2013: 68). El monumento a Garibaldi sintetizó, en función del antifascismo bahiense, esa doble dimensión del espacio público en relación con la praxis política: como su objetivo, porque se trató de un proyecto que los antifascistas locales buscaron hacer prevalecer por sobre el de sus rivales para materializar su ideología en el paisaje urbano bahiense; y como su escenario, ya que desde su inauguración representó un hito espacial en la celebración de actividades y conmemoraciones. Es por ello que es preciso tener en cuenta aquellos enfoques geográficos que nos permitan ahondar en las relaciones entre espacio y política a partir de los monumentos.

4. Todas las fuentes periodísticas consultadas se encuentran en la Biblioteca Popular Bernardino Rivadavia de Bahía Blanca. Para un análisis más detallado sobre cada órgano de prensa en particular, consultar Cernadas y Orbe (2013).

5. La totalidad de la documentación aludida se encuentra en la Sociedad Italiana de Socorros Mutuos de Bahía Blanca. 


\section{Los monumentos como formas simbólicas espaciales de la política}

Consideramos provechoso iniciar este apartado incorporando las reflexiones realizadas por Doreen Massey (2009) sobre las relaciones entre espacio y política. La autora considera que esas relaciones permiten un reconocimiento del carácter dinámico del espacio como elemento en construcción/destrucción/ reconstrucción mediante las disputas políticas.

Así entendido, el espacio es producto de una construcción social y relacional, como lo reconoce Roberto Lobato Corrêa (2011) al analizar las dimensiones culturales y políticas de la acción humana sobre el espacio. El autor considera que las relaciones entre el espacio y las formas simbólicas son bidireccionales, en la medida en que estas últimas «incorporan atributos ya conferidos a determinadas localizaciones e itinerarios, y estos son afectados por la existencia de ciertos objetos y flujos» (Lobato Corrêa, 2011: 24). En otras palabras, las formas simbólicas espaciales implican una imposición de significados al espacio, que es resultado de un proceso complejo y pluridimensional.

Entre los diferentes ejemplos posibles de formas simbólicas espaciales, pueden incluirse sin duda los monumentos, que a partir del trabajo fundacional de David Harvey (1979) no han permanecido desatendidos por las geografías culturales (entre otros, Hershkovitz, 1993; Johnson 1994, 1995; Osborne, 1998; Atkinson y Cosgrove, 1998; Whelan, 2002; Hay et al., 2004; Lobato Corrêa, 2005; Benton-Short, 2006). En efecto, en tanto en cuanto los monumentos «han sido el foco para la participación colectiva en la política y en la vida pública» (Johnson, 1995: 51) ${ }^{6}$, los mismos constituyen una fuente de análisis de utilidad para el estudio de las manifestaciones espaciales de los procesos de construcción de identidades (Johnson, 1995), así como la construcción o la contestación del poder (Lobato Corrêa, 2005).

En esta línea argumental, la posibilidad de pensar los monumentos como parte del paisaje cultural y como expresiones de la relación entre las personas y el espacio (Auster, 1997) conlleva el reconocimiento del hecho de que el paisaje cultural revela un patrón de poder y es consecuencia de procesos históricos sociales que le dan forma en el tiempo (Rowntree y Conkey, 1980: 459).

Entonces, los monumentos poseen la capacidad de impregnar el paisaje de símbolos con significados variables (Lobato Corrêa, 2005), que actúan como mecanismos para controlar el flujo de información (Rowntree y Conkey, 1980: 160) y, por lo tanto, retomando la idea de Pierre Rosanvallon (2003: 16) reproducida más arriba, como instrumentos para la construcción de reglas sobre lo socialmente compartible. Desde esta perspectiva, los monumentos pueden no ser vistos únicamente como elementos para la construcción o la invención de la identidad nacional (Anderson, 1983; Hobsbawm y Ranger, 1983; Hobsbawm, 1990), sino también para la disputa simbólica por los significados atribuidos a ella, como procuramos mostrarlo para el caso que nos ocupa.

6. Todas las traducciones son nuestras. 
De esta manera, siguiendo a Martin Auster (1997: 220), podemos considerar los monumentos como alegorías, esto es, como mecanismos de representación de ideas que van más allá de los objetos en sí mismos y que, por su perdurabilidad en el tiempo, adoptan un carácter narrativo (Auster, 1997: 221) que les permite una comunicación permanente de significados, sujeta a una pluralidad de interpretaciones por parte de los observadores (Lobato Corrêa, 2005).

Puede afirmarse que los monumentos, lejos de cumplir simplemente una función ornamental en el espacio público, son «intentos conscientes de solicitar la participación pública en la política cotidiana» (Johnson, 1994: 78), por medio de los cuales distintos sectores sociales vehiculan sus intereses políticos. Esto implica, siguiendo a James Duncan (1989: 185), la imposibilidad de realizar un análisis compartimentado de los distintos elementos en juego (tales como la cultura, la política y el espacio), puesto que tanto el emplazamiento y las formas de un monumento como los discursos que articula se revelan interconectados en función de un proyecto ideológicamente orientado. En este punto, resulta interesante incorporar las reflexiones de Antonio Carlos Robert Moraes (1988) sobre el concepto de "ideologías geográficas", aplicado al caso del Monumento a los Bandeirantes de São Paulo por Luiz Lopes Diniz Filho (1993). Esta perspectiva, que parte de la base de que las ideologías pueden expresarse materialmente, introduce la política como elemento de análisis inseparable de la cultura a la hora de abordar discursos y acciones sobre el espacio (Diniz Filho, 1993: 67). A partir de estos aportes, podemos considerar el monumento a Garibaldi como una «representación objetual», esto es, «un símbolo material que actúa como parte de una estrategia para construir y hacer reconocer una determinada identidad social» (Diniz Filho, 1993: 78), en nuestro caso, simultáneamente nacional/ étnica (italiana) y política (antifascista, republicana, democrática, liberal).

Por todo lo anterior, en nuestro análisis de los significados atribuidos por los antifascistas bahienses al monumento a Garibaldi, intentamos articular las tres nociones (cultura, política y espacio) valiéndonos de algunas de las herramientas analíticas propuestas por Lobato Corrêa (2005) y por Federico Bellentani y Mario Panico (2016). En conjunto, pretendemos aplicar al monumento a Garibaldi de Bahía Blanca un análisis holístico que permita tanto analizarlo en sí mismo como insertarlo en su contexto cultural, político y espacial de origen.

En relación con ello, y prestando atención a las conexiones señaladas, antes de abocarnos al caso bahiense es preciso realizar una caracterización de los modos en que fascistas y antifascistas compitieron por el legado de Garibaldi en Italia, en el contexto de los intentos de apropiación del pasado que el movimiento liderado por Benito Mussolini puso en marcha tras su llegada al poder.

\section{Un héroe nacional en disputa: la figura de Garibaldi entre el fascismo y el antifascismo}

Los vínculos del fascismo con el legado histórico de la unificación italiana estuvieron presentes desde los inicios del movimiento, ya que se ligó el culto 
a los caídos durante la Primera Guerra Mundial a los valores del Risorgimento (Gentile, 2007: 43). De este modo, el propio Mussolini indicó a fines de 1920 que la labor del fascismo consistía en «traducir en hechos la que fue la aspiración de Giuseppe Mazzini: dar a los italianos el "concepto religioso de nación"» (Gentile, 2007: 46).

En este contexto, la figura que nos interesa no permaneció inmune a los intentos de apropiación por parte del fascismo. Giuseppe Garibaldi (Niza, 4 de julio de 1807 - Caprera, 2 de junio de 1882) tuvo un reconocido papel como artífice en el proceso de unificación italiana, en función de sus expediciones militares contra el Reino de las Dos Sicilias al frente de un colectivo reconocido como los «camisas rojas» (Duggan, 2017: 150-154). El carisma de Garibaldi y el exotismo que rodeaba su figura por su exilio americano y

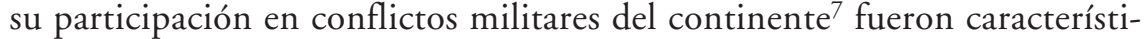
cas que lo presentaron como un personaje que coincidía con la necesidad del incipiente reino de construir un modelo de héroe romántico capaz de infundir sentimientos de nacionalidad y patriotismo a los nacientes italianos (Lyttleton, 2012: 37-38).

La consagración de Garibaldi como héroe nacional y también la fascinación que su figura ejercía en la población lo convirtieron en una referencia insoslayable en el panteón de los líderes que representaban el espíritu originario del Risorgimento, por lo que tanto fascistas como antifascistas buscaron dotarlo de sentidos propios que les permitieran apropiarse de su popularidad y representatividad. Al respecto, Fabrizio Soriano (2010: 100-101) señala que el fascismo buscó mostrarse como heredero y continuador de un legado que se presentaba como antitético al liberalismo parlamentario exaltando la "continuidad entre la epopeya garibaldina y la revolución fascista» (Soriano, 2010: 103) y subrayando que esta última no solo había contribuido a mantener el espíritu de la primera, sino también a perfeccionarlo mediante la regeneración de la nación y su integración total al Estado. Frente a esto, el autor sostiene que, aun cuando no faltaron intentos por parte de los opositores de Mussolini de realizar una interpretación antifascista del mito de Garibaldi, «parece difícil rastrear una capacidad movilizadora en este sentido de la tradición y el mito garibaldinos, al menos hasta 1936» (Soriano, 2010: 98), cuando los voluntarios italianos de las brigadas internacionales comenzaron a adoptar el nombre y la imagen de Garibaldi durante la Guerra Civil Española.

Si bien esto último puede ser válido para el contexto italiano, marco en el cual Soriano realiza su estudio, no lo es en el contexto particular que analizamos: en Argentina, así como en otros países sudamericanos receptores del flujo

7. Garibaldi participó en el bando separatista durante la Guerra de los Farrapos (1834-1845), que enfrentó a los estados brasileños de Santa Catarina y Rio Grande do Sul contra el Imperio del Brasil (Hartmann, 2002), así como en la Guerra Grande (1839-1851), cuando apoyó al gobierno colorado de Fructuoso Rivera en Uruguay y se enfrentó a los blancos liderados por Manuel Uribe y apoyados por la Confederación Argentina, gobernada por Juan Manuel de Rosas (Halperín Donghi, 2005: 199-201). 
migratorio italiano, entre los que se destacan Brasil y Uruguay, Garibaldi también se había convertido tempranamente en un símbolo nacional central para la identidad de los inmigrantes (Goebel, 2014: 248). Consecuentemente, cuando el Gobierno italiano avanzó en su intento de fascistizar a sus connacionales en el extranjero, lo que despertó las reacciones del antifascismo en las colectividades, ambos bandos en pugna "combinaron la italianidad con sus propias ideologías políticas» (Aliano, 2012: 7). De este modo, mientras los fascistas reproducían los discursos ya aludidos sobre la continuidad entre camisas rojas y negras, los antifascistas italianos en Argentina sostenían que el fascismo representaba «una perversión del verdadero carácter nacional de Italia, cuyos orígenes yacían (...) en el humanismo universal del Renacimiento y en el idealismo democrático de Mazzini y Garibaldi» (Aliano, 2012: 126). Desde esta óptica, el antifascismo recuperaba el legado de su participación en distintos conflictos sudamericanos entre 1835 y 1848 , de forma que lo interpretaba en el sentido de una «lucha contra la tiranía en las Pampas» (Aliano, 2012: 98). Luego, la progresiva llegada de exiliados antifascistas a Argentina contribuyó a forjar esta comunión entre la figura de Garibaldi vista en clave liberal y el movimiento antifascista italiano que comenzó a articularse en las principales ciudades del país.

En el caso bahiense, que analizamos a continuación, la figura de Garibaldi representó un elemento aglutinador al que el antifascismo local se vio prontamente ligado y que logró materializarse en el monumento del que nos ocupamos en este trabajo. Por lo tanto, antes de proceder al análisis del monumento a Garibaldi, resta realizar una breve reseña histórica sobre la colectividad italiana en Bahía Blanca, centrada de modo particular en el impacto que ocasionó en su seno el ascenso del fascismo en Italia.

\section{Los italianos de Bahía Blanca ante el advenimiento del fascismo}

El aporte socioeconómico y cultural de la corriente migratoria italiana a la sociedad argentina es un tema que no ha sido desatendido por la historiografía (entre otros, Devoto y Míguez, 1992; Devoto y Rosoli, 2000; Devoto, 2006), principalmente en función de la profundidad del impacto demográfico que ese conjunto poblacional tuvo en el país durante el período de la inmigración masiva (1880-1914). En el censo de 1914 se contaban 929.863 italianos, que representaban un $11,79 \%$ del total de la población del país, lo que los constituía en la principal colectividad extranjera, por encima de los españoles $(829.701)^{8}$. Ese porcentaje general era superado por los que alcanzaba la población italiana en los principales centros urbanos del área pampeana, tales como la ciudad de Buenos Aires $(19,83 \%)^{9}$, Rosario $(18,50 \%)^{10}$, Santa Fe

8. Tercer Censo Nacional, tomo II, pp. 395-396.

9. Ídem, pp. 148-149. En todos los casos que se suceden las cifras hacen alusión exclusivamente a población urbana.

10. Ídem, pp. 230-231. 
$(17,54 \%)^{11}$, La Plata $(16,98 \%)^{12}$ y Avellaneda $(16,60 \%)^{13}$. En el partido de Bahía Blanca, la proporción de la población italiana por sobre la totalidad de la población urbana era del $19,71 \%^{14}$, apenas menor a la de la Capital Federal y superior tanto a la que encontramos en las restantes localidades destacadas como a la media de la provincia de Buenos Aires $(14,44 \%)^{15}$.

En cuanto al caso bahiense en particular, el impacto de la inmigración italiana ha sido tratado en el contexto general de la inmigración ultramarina en la ciudad (López de Pagani et al., 1971; Weinberg y Buffa de Bottaro, 1982; Caviglia, 1984; Monacci, 1988). No obstante, ninguno de los estudios al respecto se ha enfocado en el impacto que el advenimiento del fascismo tuvo en la colectividad italiana bahiense, temática que sí ha sido abordada en el ámbito nacional (entre otros, Gentile, 1986; Newton, 1994; Zanatta, 2003; Grillo, 2006; Scarzanella, 2007: 167-338; Prislei, 2008; Finchelstein, 2010; Aliano, 2012; Sergi, 2012: 217-280; Fotia, 2015).

La historia del impacto del fascismo en Argentina no puede analizarse aisladamente en el contexto general de la proyección exterior de esa ideología, que tuvo en los Fasci Italiani all'Estero su principal vector. Surgido espontáneamente a la par de los orígenes del movimiento fascista en Italia en la primera posguerra, el movimiento fascista de los italianos emigrados fue progresivamente dominado por el Gobierno italiano, hasta alcanzar su total institucionalización en la segunda mitad de los años 20 (González Calleja, 2012: 30-34). En nuestro país, solo el fascio de Buenos Aires surgió de manera autónoma, y fue el primero en el país y en toda Latinoamérica tras su fundación en octubre de 1922 (Devoto, 2006: 345). Por su parte, la organización de una institución de estas características en Bahía Blanca se dio en mayo de 1926, cuando fue oficialmente establecido el fascio Giulio Giordani con un importante apoyo logístico del Viceconsulado de Italia (Cimatti, 2016a: 124-125). No obstante, la institución representó una de las primeras de su tipo en el país, si se tiene en cuenta que en 1925 se contaban tan solo ocho fasci en todo el territorio argentino (Caprariis, 2000: 158).

La aparición de la primera institución fascista en la esfera pública bahiense implicó una serie de transformaciones profundas en el marco de la sociabilidad de la colectividad italiana, al marcar el inicio de una polarización entre los sectores que se adhirieron al fascismo y los que se resistieron a la nueva ideología imperante en Italia.

En cuanto a los primeros, progresivamente adoptaron formas de sociabilidad propias de los sectores dominantes de la sociedad bahiense, tales como

11. Ídem, pp. 220-221.

12. Ídem, pp. 149-150.

13. Ídem, pp. 153-154.

14. Ídem, pp. 155-156. En el censo se presentan las cifras poblacionales distinguiendo su carácter urbano o rural para la totalidad del partido. De los 62.191 habitantes urbanos del partido de Bahía Blanca, 44.143 residían en la ciudad homónima. Los restantes se repartían tanto en los otros dos centros urbanos del partido, a saber, Punta Alta (8.120) e Ingeniero White (5.368), como en localidades más pequeñas del mismo.

15. Ídem, pp. 219-220. 
banquetes, festivales teatrales o conferencias (Cimatti, 2016b), lo que los alejaba del carácter popular (y en ocasiones violento) que el fascismo all'estero había adoptado en grandes centros urbanos como Nueva York (Cannistraro, 1999) o París (Milza, 1983), o incluso en algunas otras localidades argentinas, entre las que destacan los casos de Buenos Aires y Avellaneda (Capizzano, 2013). Por su parte, los sectores antifascistas de la colectividad italiana bahiense se nuclearon fuertemente en torno del Centro Socialista de Bahía Blanca, comité local del Partido Socialista, que tuvo un rol activo en el campo antifascista local, lo que permite al menos matizar la idea difundida de que durante la década de 1920 la resistencia antifascista de los italianos había permanecido sectarizada étnicamente (Bisso, 2001: 212) ${ }^{16}$.

En otras palabras, la disputa entre fascismo y antifascismo en la ciudad no adoptó características vinculadas al uso de la violencia física ${ }^{17}$, ni tampoco una ocupación relevante del espacio público ${ }^{18}$. No obstante, aunque la confrontación entre ambos bandos no tuvo el cariz que adquirió en otros lugares, los fascistas y antifascistas de Bahía Blanca libraron una silenciosa disputa por la hegemonía en la colectividad italiana local.

El primer enfrentamiento entre ambos sectores tuvo lugar durante las elecciones de la Sociedad Italiana de Socorros Mutuos e Instrucción Italia Unita en enero de 1927, cuando se enfrentaron la lista oficialista, compuesta principalmente por dirigentes de larga trayectoria que en mayo del año previo habían comenzado a formar parte del fascio bahiense, y la lista opositora Italia Libera, patrocinada desde el Centro Socialista local y el recientemente creado Centro Antifascista Giacomo Matteotti (Cimatti, 2016a). Los comicios arrojaron un resultado favorable a la lista antifascista, lo que implicó un cambio que alteró los proyectos que, meses antes, se venían formulando para la participación de la colectividad italiana en los festejos por el centenario de la ciudad.

\section{Los antifascistas bahienses y el monumento a Garibaldi}

Los orígenes del monumento a Garibaldi se enmarcan en los inicios de la disputa entre fascistas y antifascistas en la ciudad. El centenario de Bahía Blanca, a celebrarse en abril de 1928, había suscitado el interés de los sectores dirigentes

16. Hacia el período estudiado, y si bien el Centro Socialista contaba entre sus filas con afiliados de origen italiano $(14,56 \%)$, el grueso de los afiliados estaba constituido por argentinos $(46,20 \%)$ y españoles $(32,28 \%)$ (Cabezas, 2013), por lo que la vinculación entre los antifascistas italianos y el Centro puede verse como un rasgo de apertura de los primeros hacia actores sociales ajenos a la propia colectividad.

17. Se registraron enfrentamientos violentos en otras localidades del interior argentino tales como Córdoba, donde en 1923 simpatizantes fascistas se hicieron con el control por la fuerza del local de los Reduci della Grande Guerra (Vagliente, 2016: 261), o en Mendoza, donde los fascistas asesinaron al militante antifascista Camillo Nardini en 1926 (Devoto, 2006: 345).

18. La afirmación vale para los fascistas locales, y resulta especialmente significativa en este punto la ausencia de movilizaciones en calles o plazas tras la conquista de Etiopía y la creación del Imperio (Cimatti, 2017: 86-89). 
de la colectividad, ya desde 1926, por decidir cuál sería el obsequio que harían a la ciudad en su aniversario. Es preciso recordar que, por ese entonces, la cúpula de la Sociedad Italia Unita aún se hallaba estrechamente vinculada al Viceconsulado de Italia, ya que desde la fundación de la entidad, en 1912, varios de quienes la conformaban eran flamantes miembros del fascio local (Cimatti, 2016a: 124). En ese contexto, en octubre de 1926, la directiva entrevistó al vicecónsul Giorgio Foresti, quien se había comprometido a hacerse cargo del proyecto para la construcción de una fuente luminosa en obsequio a la ciudad subrayando que la iniciativa había partido de la entidad mutual ${ }^{19}$.

Las reuniones con el vicecónsul se repitieron durante los meses sucesivos ${ }^{20}$, lo que permite suponer un cierto desarrollo en el proyecto a realizar ${ }^{21}$, pero las elecciones generales de la institución implicaron un quiebre al arrojar como vencedora a la lista Italia Libera, que buscaba «librar a la Sociedad de las manos de los fascistas locales ${ }^{22}$. Consecuentemente, la victoria de la lista antifascista implicó el conflicto y el posterior distanciamiento con el Viceconsulado local, principal representante del gobierno fascista en la ciudad. Finalmente, en marzo de 1927, el Consejo Directivo de la entidad mutual realizó una reprobación pública al vicecónsul Foresti por su adhesión al fascismo ${ }^{23}$.

Las diferencias entre la Sociedad y el Viceconsulado tuvieron uno de sus momentos más álgidos en la decisión sobre cuál sería el obsequio de la colectividad italiana a la ciudad. En mayo de 1927, se conformaron con tal propósito dos comisiones paralelas, auspiciadas respectivamente por el vicecónsul de Italia y por Marzio Cantarelli, el nuevo presidente de la Socie$\mathrm{dad}^{24}$. La presencia simultánea de ambas comisiones no puede sino ser vista como una disputa política por ocupar, ante la vista de la sociedad bahiense en su conjunto, el rol preponderante en la colectividad italiana. De hecho, la competencia se hizo palpable en una comunicación realizada por Cantarelli ante los miembros del Consejo Directivo en la que resumían los resultados de un intercambio con el vicecónsul, cuando afirmó que Foresti sostenía que debía ser la «autoridad italiana» quien estuviera al frente de tal «demostración colectiva», idea a la que el presidente se oponía ${ }^{25}$. Si bien los archivos no permiten dar cuenta de la posición de poder relativo de cada una de las comisiones, un comunicado publicado en la prensa por parte de miembros

19. Sesión ordinaria del 18/10/1926, Libro Verbali del Cons/Dirett. Redatti in Italiano, pp. 96-97.

20. Sesión ordinaria del 30/11/1926, Libro Verbali del Cons/Dirett. Redatti in Italiano, p. 103; y sesión ordinaria del 08/12/1926, Libro Verbali del Cons/Dirett. Redatti in Italiano, p. 106.

21. Si bien en los archivos societarios se encuentran menciones al proyecto, no se conserva ningún plano o boceto de la obra proyectada, lo que impide realizar un análisis comparativo de la misma en función del monumento a Garibaldi.

22. Nuevos Tiempos, $12 / 01 / 1927$, p. 3 .

23. Sesión extraordinaria del 11/03/1927, Libro Verbali del Cons/Dirett. Redatti in Italiano, pp. 130-131.

24. La Nueva Provincia (LNP), 25/05/1927, p. 11, y 29/05/1927, p. 6.

25. Sesión extraordinaria del 21/04/1927, Libro Verbali del Cons/Dirett. Redatti in Italiano, pp. 140-141. 
de la que presidía el vicecónsul permite suponer que su posición era la menos favorecida ${ }^{26}$.

Finalmente, en julio de 1927 la prensa anunció que se había decidido llevar a la práctica el proyecto propuesto por el presidente de la Sociedad Italia Unita de erigir un monumento a Garibaldi en una de las plazoletas situadas a los lados del Teatro Municipal, en la intersección de las calles Dorrego y Alsina ${ }^{27}$. En esa ocasión, Cantarelli pronunció un discurso para promocionar su proyecto, en el que recalcó que la figura que se iba a representar era portadora de una innegable italianidad, pero remarcó también su trayectoria como militar en Argentina, Uruguay y Brasil, a los que buscó liberar «del yugo de los tiranos» ${ }^{28}$. Esta visión volvió a ser puesta de relieve en los actos por la colocación de la piedra fundamental del monumento, cuando el cónsul de la República Oriental del Uruguay, Andrés Muñoz Anaya, estuvo a cargo de un discurso sobre la estancia de Garibaldi en el subcontinente ${ }^{29}$.

El monumento fue diseñado y construido por el artista italiano Giuseppe Vasco Vian ${ }^{30}$, y consiste en una estatua de bronce ubicada sobre un pedestal de granito que alcanza los ocho metros de altura (Ribas y Tolcachier, 2012: 64). Una nota redactada de manera anónima por un crítico y publicada en la prensa local permite recuperar una interpretación contemporánea de los contenidos simbólicos que el monumento corporizaba: Garibaldi era presentado vistiendo la icónica camisa roja, apoyado sobre su espada con la mano izquierda, mientras con la derecha agitaba un sombrero brasileño «saludando al pueblo ya libre del absolutismo del poder que acababa de aniquilar ${ }^{31}$. El objetivo final era, por lo tanto, perpetuar al héroe en el bronce "para que el recuerdo permanezca latente en el corazón de todo italiano bien nacido que ame verdaderamente a su patria» ${ }^{32}$. Es posible ver cómo, en conjunción con la visión de Garibaldi como un paladín liberal, se hacía énfasis en la identidad de los italianos y su identificación con su héroe nacional ${ }^{33}$.

Entre otras características del monumento, resalta la imagen de un león reposando sobre el pedestal, que representa los últimos años de Garibaldi en la isla de Caprera. Además, pueden considerarse atributos del monumento tres placas de bronce que, si bien no formaban parte del diseño original, aparecieron tempranamente en el pedestal del monumento. La primeras dos fueron colocadas el día de su inauguración: una registra la erección del monumento

26. Los representantes de la comisión expresaron su deseo de «obtener la fusión con aquellas otras comisiones que puedan constituirse con el mismo objeto". LNP, 31/07/1927, p. 14.

27. $L N P, 03 / 07 / 1927$, p. 8.

28. Ibidem.

29. $L N P, 26 / 09 / 1927$, p. 14.

30. El artista se había exiliado en Argentina dos años antes y se había instalado en la cercana localidad de Tres Arroyos, donde desarrolló sus primeros trabajos. LNP, 30/09/1927, p. 9.

31. Ibidem.

32. Ibidem.

33. Esta visión se revela en sintonía con los significados nacionalistas de los que la élite dirigente de la colectividad italiana porteña buscó dotar al monumento a Garibaldi erigido en la plaza Italia de la ciudad de Buenos Aires (Dosio, 2010). 
como iniciativa de las sociedades italianas de la ciudad y la región ${ }^{34}$, mientras que la otra fue donada por la Logia Masónica Italiana Nadir. Posteriormente, en 1929 se insertó una tercera placa, esta vez por parte del Centro Republicano Italiano, dedicada al «eterno heraldo de la libertad ${ }^{35}$. Puede apreciarse así que el monumento fue tempranamente intervenido por organizaciones que conformaban el campo antifascista bahiense, de forma que se materializó en el monumento su apropiación de la figura de Garibaldi.

Para nuestro análisis del monumento, retomamos la distinción realizada por Lobato Corrêa (2005) en lo referente al emplazamiento. Su localización absoluta, en una de las plazoletas que flanquean el Teatro Municipal de Bahía Blanca $^{36}$, le otorgaba una relevante localización relativa, por hallarse a pocas manzanas de la Municipalidad y a metros de la avenida Alem, en la que habitaban los sectores sociales más encumbrados de la ciudad. Por último, si consideramos la noción de localización relacional planteada por el autor, vinculada a los significados atribuidos a la misma por los diversos grupos sociales, podemos percibir que la misma otorgó al monumento una importante relevancia sociocultural en el espacio público bahiense.

En lo referente a la escala, entendida por Lobato Corrêa (2005) tanto en su dimensión absoluta como relacional, puede observarse que, en función de la primera (ocho metros de altura total), la segunda muestra un monumento modesto en comparación con otros similares, como el erigido a Garibaldi situado en la plaza Italia de Buenos Aires e inaugurado en 1904: esa obra, en la que una estatua ecuestre se asienta sobre un basamento que incluye referencias alegóricas a Argentina e Italia y a batallas icónicas de la trayectoria militar de Garibaldi, cuenta con más de quince metros de altura (Dosio, 2010: 75-76). No obstante, si se analiza el monumento que nos interesa en función de la estatuaria bahiense del período, su dimensión relacional cobra más relevancia, ya que era uno de los monumentos de mayor envergadura en el acotado acervo monumental de la ciudad ${ }^{37}$.

La obra se inauguró oficialmente el 11 de abril de 1928 en un acto que contó con la presencia de las autoridades locales, a quienes el representante de

34. La iniciativa de la entidad mutual bahiense fue secundada por sus homólogas de Punta Alta (actual cabecera del vecino partido de Coronel Rosales, conformado en 1945 con tierras pertenecientes al partido de Bahía Blanca), Ingeniero White, Cuatreros (hoy General Daniel Cerri) y Cabildo.

35. LNP, 23/09/1929, p. 15.

36. El teatro, inaugurado en 1913, representó desde sus orígenes uno de los centros cultuales de la ciudad y la región. Entre los más destacados artistas de la época que lo visitaron, se incluyen figuras como Luigi Pirandello, Lola Membrives, Carlos Gardel y Leopoldo Marechal, entre otros.

37. En contraste con la ciudad de Buenos Aires, cuya política estatuaria se considera iniciada con la construcción de la Pirámide de Mayo en 1811 (Dosio, 2010: 73), el primer monumento erigido en Bahía Blanca fue una estatua ecuestre del general José de San Martín en el Parque de Mayo, con motivo del centenario de la Revolución de Mayo, celebrado en 1910. Como resultado de este tardío desarrollo, la ciudad no contaba hacia su centenario con una gran cantidad de monumentos en el espacio público. 
la comisión encargada de la construcción del monumento manifestó la voluntad de que recordara «a la gran Nación Argentina el cariño profundo que para ella guardamos en nuestros pechos y la admiración por su grandeza histórica y social que la destaca entre los pueblos de la tierra ${ }^{38}$.

Esto nos permite adentrarnos en una tercera dimensión de la escala, también introducida por Lobato Corrêa (2011: 25): la dimensión espacial, es decir, el alcance espacial que se busca dar a la estructura. En relación con ella, la figura de Garibaldi evocaba la patria de origen, pero también la de arribo, lo que puede apreciarse en la reconstrucción presentada de la figura de Garibaldi, que implicaba un entrecruzamiento entre Italia y América (y más precisamente Argentina), y enfatizaba la condición migratoria compartida por el prócer italiano y la mayoría de los miembros de la colectividad italiana local. No obstante, el monumento no implicaba solamente una relación simbólica con el pasado italiano y el argentino, ya que el pasado también es "proyectado para el futuro por medio de una forma simbólica» (Lobato Corrêa, 2011: 36). Así, el carácter libertario de la lucha garibaldina no pasaba desapercibido en el contexto de la época, a seis años del ascenso al poder de Mussolini. En otras palabras, la figura de Garibaldi evocaba la lucha que los antifascistas del mundo libraban contra el gobierno fascista allí donde este se presentara, como estaba sucediendo desde 1926 en Bahía Blanca.

En este punto, es interesante reflexionar sobre el modo en que, al privilegiar una u otra escala, pueden apreciarse diferentes significados políticos del monumento. En efecto, si se lo analiza a partir de la dimensión espacial planteada por Lobato Corrêa (2011: 25) que referimos más arriba, el alcance político que revistió el monumento le daba un carácter de resistencia ante el fascismo que imperaba en Italia y buscaba subordinar a las colectividades de emigrantes en todo el mundo. Sin embargo, si se lo analiza desde su posición en el campo bahiense, la edificación del monumento propuesto por el antifascismo no representó un acto de resistencia al poder, sino, por el contrario, una manifestación geográficamente situada del poder con que contaban los antifascistas en tiempos del centenario local.

Esta interpretación dual nos permite incluir otra dimensión, la política, tal como la consideran Bellentani y Panico (2016: 37-39). Los autores sostienen que los monumentos son producidos por las élites en función de sus intereses "para promover narrativas históricas selectivas y dominantes» (Bellentani y Panico, 2016: 37).

La perspectiva planteada por los autores puede aplicarse al caso del monumento a Garibaldi de Buenos Aires, en cuya construcción la élite de la colectividad italiana encontró un medio para acercarse a la oligarquía argentina al insertar el monumento en el proyecto de construcción de la nación argentina, como afirma Patricia Dosio (2010: 79-82), mediante la incorporación de los italianos a la misma. En esa ocasión, la élite de la colectividad logró arrogarse la representación del conjunto de los italianos «dotándolo de una identidad y

38. LNP, 13/04/1928, p. 14. 
reinventando una tradición al recuperar selectivamente recursos de su pasado» (Dosio, 2010: 82). La autora presenta la imagen de una élite homogénea que buscaba manifestar su poder tanto hacia adentro de la comunidad, mediante la generación de una identidad común, como de cara a la clase política argentina, al presentarse como un interlocutor de relevancia, por lo que el monumento puede ser interpretado como una herramienta política de esa élite para legitimar su poder.

Sin embargo, cuando se analiza el caso del monumento a Garibaldi de Bahía Blanca, la situación adopta características que tensionan la visión de la dimensión política planteada por Bellentani y Panico. En el caso analizado, el contexto novedoso de la disputa entre fascismo y antifascismo alteró las pautas sociales de la colectividad italiana local, lo que impide entre otras cosas hablar de una élite homogénea al frente de la misma, ya que tanto el bando antifascista como el fascista contaban entre sus filas con prominentes individuos, cuyo prestigio derivaba de la posición económica que habían alcanzado y de los vínculos que detentaban con figuras destacadas de la sociedad bahiense. Por ejemplo, el ya mencionado Cantarelli, presidente de la Sociedad Italia Unita, era uno de los empresarios de la construcción más reconocidos de la ciudad, y su poderío económico resaltaba hasta el punto de ser uno de los principales sostenedores del Centro Socialista local. Por su parte, entre los fascistas locales, se contaba con Luigi Godio, propietario de uno de los principales molinos harineros de la ciudad, así como del reconocido Hotel D'Italia.

Consecuentemente, podemos pensar que la erección del monumento a Garibaldi por parte del antifascismo local no fue la manifestación de la voluntad de una élite étnica de manifestar su poder hacia los connacionales que decía representar o hacia la dirigencia política bahiense, sino que más bien representó un gesto de demostración de poder en el contexto de una disputa intraélite por el sentido político que se atribuiría a la colectividad italiana local. Esta mirada nos permite poner el foco en la disputa de fondo: definir si se podía mostrar a los italianos de Bahía Blanca como una unidad compacta en contra o a favor del gobierno de Mussolini.

En este punto, cabe recuperar algunas de las reflexiones realizadas por Diniz Filho (1993) sobre el Monumento a los Bandeirantes, erigido por la élite paulista de la primera mitad del siglo xx, y que el autor analiza como una representación objetual que buscó construir y difundir una identidad social (en su caso nacional y regional) en el marco de la lucha simbólica entablada con las élites nordestinas por la construcción de la identidad nacional de Brasil. El caso analizado por Diniz Filho, a pesar de sus diferencias, tiene importantes similitudes con la cuestión que nos ocupa, ya que el monumento a Garibaldi también puede considerarse una representación objetual en el marco de la lucha simbólica que fascistas y antifascistas libraron para incorporar sus proyectos a la identidad nacional italiana o, más aún, para apropiarse de esta última (situación que aparece complejizada por el hecho de que el proceso migratorio implicó que tal proceso se diera en una sociedad distinta a la de origen). Desde esta óptica, el monumento buscó articular la identidad nacional/étnica 
italiana con la identidad política antifascista, expresada en los valores liberales atribuidos a Garibaldi como héroe nacional.

Si tenemos en cuenta que «en momentos históricos particulares una visión puede adquirir un estatus hegemónico, aunque solo sea momentáneamente, incluso cuando los procesos involucrados en [su] creación son polisémicos y fragmentados" (Johnson, 1994: 79), puede considerarse que en el caso analizado los antifascistas lograron erigir el monumento a Garibaldi (en tanto representación objetual), impregnado de un contenido libertario y antifascista, como obsequio a la ciudad, para materializar y perpetuar la victoria obtenida sobre los fascistas tras las elecciones de la Sociedad Italia Unita de 1927.

\section{Consideraciones finales}

El título de este trabajo plantea una pregunta que no da lugar a respuestas simples ni unívocas en cuanto a los sentidos que el monumento a Garibaldi adquirió durante el período estudiado. El análisis de los monumentos como formas espaciales o representaciones objetuales capaces de transmitir nociones de identidad y poder nos planteó el interrogante aludido, esto es, qué función o rol cumplió el emplazamiento de la obra en el espacio público bahiense por parte del antifascismo local.

Así, desde la perspectiva identitaria, el monumento pudo haber funcionado, de manera similar a la que lo hizo en el caso porteño, como un elemento aglutinador de carácter nacional y, de este modo, como una reafirmación de la presencia italiana en la ciudad que pusiera de relieve su importancia en el desarrollo económico y social local y regional. No obstante, como desarrollamos más arriba, esa noción no encaja (o al menos no del todo) con la imagen de una dirigencia étnica profundamente dividida por cuestiones políticas, en el marco de la cual se produjo una lucha simbólica por dotar a esa identidad nacional/ étnica de sentidos políticos determinados. Por otra parte, desde la perspectiva del poder, vimos que el monumento (según el recorte espacial con que se lo analice) pudo representar tanto una materialización de hegemonía como una manifestación de resistencia por parte del sector antifascista.

Creemos que el hecho de que las tres nociones (reivindicación identitaria, demostración de hegemonía o manifestación de resistencia) puedan aplicarse limitada pero conjuntamente al monumento no indica una dificultad en el análisis, sino que, por el contrario, revela el aspecto de mayor interés. En efecto, si retomamos la idea de los monumentos como alegorías, comprendemos que el significado de las mismas "posee una cierta complejidad que opera en más de un nivel» (Auster, 1997: 220), y en la que los significados del monumento pueden ser múltiples y hallarse interconectados.

En resumen, la imagen de Garibaldi apropiada y dotada de contenidos por parte del antifascismo fue el resultado de una coincidencia de interpretaciones por parte de republicanos italianos, socialistas y masones, a partir de la cual cuajó la idea de un héroe libertario que combatió la tiranía de uno y otro lado del Atlántico, y de que tal espíritu era el que identificaba a los «verdaderos» 
Figura 3. Celebración de la Fiesta de la República Italiana, 2 de junio de 2018

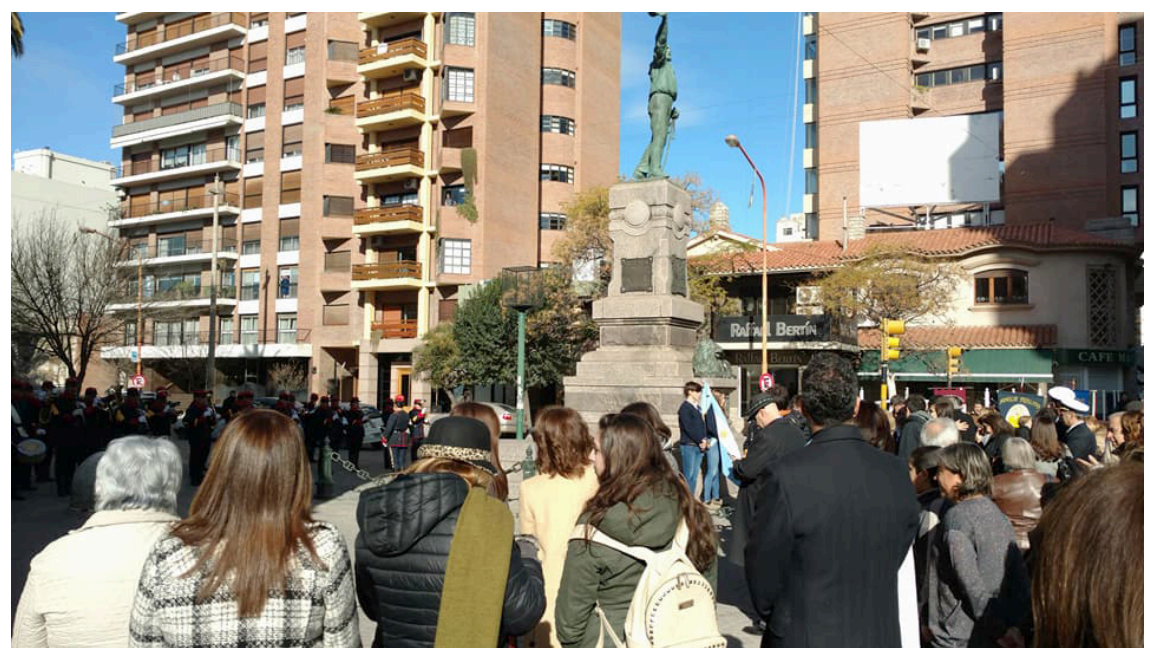

Fuente: página de Facebook de la Sociedad Italiana de Socorros Mutuos de Bahía Blanca: <https://www. facebook.com/sociedaditalianabb/photos/pcb.1751272424916687/1751272321583364/?type=3\&theater>.

italianos. De esta manera, el monumento expresó los vínculos entre los inmigrantes italianos y su patria de arribo, pero también implicó una declaración de principios políticos.

Para concluir, y pese a alejarnos del período histórico que enmarcó el trabajo, consideramos interesante recuperar la pervivencia del monumento como un espacio central para la vida de la colectividad italiana local, ya que es el lugar en el que cada 2 de junio, Fiesta de la República Italiana, se reúne la colectividad italiana (figura 3).

Sin embargo, en la actualidad, el monumento ya no tiene un significado político basado en la confrontación ideológica (ignorada por muchos de quienes circulan cotidianamente a su alrededor), sino que su significado ha permanecido fundamentalmente vinculado a la evocación de la patria de los antepasados (y cada vez más residualmente de la propia), lo que permite a su vez reflexionar sobre la temporalidad que impregna las formas simbólicoespaciales (Lobato Corrêa, 2011: 25) y el impacto que la misma tiene en la evolución y la variación de sus sentidos. Con todo, resulta interesante constatar que el monumento es anualmente epicentro de una celebración de carácter republicano y liberal, lo que sintoniza con los significados que originariamente le atribuyó el antifascismo bahiense. Al respecto, resulta interesante tener en cuenta que, desde 1929, el monumento sufrió una única intervención, a saber, la colocación de una cuarta placa en el año 2005 con motivo del bicentenario del nacimiento de Giuseppe Mazzini (Génova, 22 de junio de 1805 - Pisa, 10 de marzo de 1872), otro de los próceres liberales de la unificación italiana, 
quien fue destacado como «luchador por la democracia y la República». En este caso, y a diferencia de lo observado por Diniz Filho (1993: 79) para el Monumento a los Bandeirantes de São Paulo, puede considerarse que, como representación objetual, el monumento a Garibaldi se reveló eficaz, puesto que aún actualmente la colectividad reconoce en él elementos de una identidad italiana vinculada al pensamiento liberal, democrático y republicano del que buscaron impregnarlo sus ideólogos. En otras palabras, tal eficacia se manifiesta en el hecho de que, ya terminado el contexto de polarización ideológica que dio origen a sus posibles interpretaciones políticas (sea la de hegemonía o la de resistencia), y prevaleciendo su faceta identitaria ítalo-argentina, esta última aparece imbuida de valores políticos que hoy se consideran atributos de ambas repúblicas.

La actualidad y la mutabilidad de la significación del monumento son las que nos pueden permitir considerarlo, retomando a Pierre Nora, como un lugar de la memoria de la colectividad italiana bahiense, y por lo tanto constituido por la interacción entre la memoria y la historia (Nora, 2008: 33). Así, el monumento está atravesado por la doble razón de ser de los lugares de la memoria señalada por Nora (2008: 34): por un lado, la de representar una visión cerrada y detenida del pasado a recordar (la figura de Garibaldi y su «doble pertenencia» italiana y argentina/sudamericana), pero, por el otro, la de presentar una variabilidad en cuanto a sus significaciones (del antifascismo originario a una visión menos conflictiva que se desprendió de la confrontación política contra el fascismo para adoptar una perspectiva patriótica atravesada por los valores democráticos y liberales de Occidente). Además, la vinculación al concepto acuñado por Nora, surgido de la idea de que «los lugares de memoria nacen y viven del sentimiento de que no hay memoria espontánea» (Nora, 2008: 25), se revela clara en el caso que analizamos, puesto que el monumento evoca actualmente la memoria de la patria de origen de una colectividad que, en su práctica totalidad, ya no está conformada por personas provenientes de Italia, sino por sus descendientes (en muchos casos, por nietos o incluso bisnietos). Es por ello que, ante la imposibilidad de habitar una memoria con que no cuenta, la colectividad italiana de Bahía Blanca ha constituido al monumento a Garibaldi como lugar de memoria.

El monumento a Garibaldi representa, por lo tanto, una marca espacial con un contenido simbólico profundamente denso y una vigencia como forma simbólica espacial que supera por mucho el acotado marco temporal que analizamos. No obstante, consideramos que fue durante ese período cuando se articularon los significados que transformaron el monumento en un hito espacial al que, desde su inauguración, ha acudido recurrentemente la colectividad italiana local.

En resumen, nuestra contribución ha pretendido, en particular, ahondar en la comprensión del proceso de configuración y desarrollo del antifascismo en Bahía Blanca a partir del análisis de un elemento del espacio urbano que fue dotado de significados identitarios y políticos y que marcó un hito en su confrontación con el fascismo local. A su vez, y de modo más general, 
esperamos que este trabajo contribuya al campo de análisis de los monumentos como formas simbólicas espaciales de la política, mediante el análisis de un caso que pone en juego las nociones de identidad y poder en la colectividad italiana de Bahía Blanca.

\section{Referencias bibliográficas}

Aliano, David (2012). Mussolini's National Project in Argentina. Madison: The Fairleigh Dickinson University Press.

Anderson, Benedict (1983). Imagined Communities. Londres: Verso.

Atkinson, David y Cosgrove, Denis (1998). «Urban Rethoric and Embodied Identities: City, Nation and Empire at the Vittorio Emanuele II Monument in Rome, 1870-1945". Annals of the Association of American Geographers, 88 (1), 28-49. <http://dx.doi.org/10.1111/1467-8306.00083>

Auster, Martin (1997). «Monument in a landscape: the question of meaning». Australian Geographer, 28 (2), 219-227. <http://dx.doi.org/10.1080/00049189708703194>.

Bellentani, Federico y Panico, Mario (2016). "The meanings of monuments and memorials: toward a semiotic approach». Punctum. International Journal of Semiotics, 2 (1), 28-46. $<$ http://dx.doi.org/10.18680/hss.2016.0004>

Benton-Short, Lisa (2006). «Politics, Public Space and Memorials: The Brawl on the Mall». Urban Geography, 27 (4), 297-329. $<$ http://dx.doi.org/10.2747/0272-3638.27.4.297>

Bisso, Andrés (2001). «El antifascismo argentino: imagen de redención democrática de la sociedad civil en la Argentina fraudulenta y militar de los años 30 y 40 ». Trabajos y comunicaciones, 26-27, 211-232. <http://www.memoria.fahce.unlp. edu.ar/art_revistas/pr.13/pr.13.pdf s.

Cabezas, Gonzalo (2013). «Perfil sociodemográfico del Centro Socialista bahiense y trayectorias biográficas de sus afiliados a comienzos del siglo XX». XIV Jornadas Interescuelas / Departamentos de Historia. Mendoza, s/p. <http://www.aacademica. org/000-010/665>.

Cannistraro, Philip (1999). Blackshirts in Little Italy. Italian Americans and Fascism, 1921-1929. West Lafayette: Bordighera Press.

Capizzano, Hernán (2013). Presencia fascista en Argentina. Relatos y apuntes, 19301945. Buenos Aires: Memoria y Archivo.

Capraris, Luca de (2000). "Fascism for Export”? The Rise and Eclipse of the Fasci Italiani all'Estero". Journal of Contemporary History, 35 (2), 151-183. <http://www. jstor.org/stable/261202>.

Caviglia, María Jorgelina (1984). Inmigración ultramarina en Bahía Blanca. Buenos Aires: CLACSO.

Cernadas, Mabel Nélida y Orbe, Patricia Alejandra (comps.) (2013). Itinerarios de la prensa. Cultura politica y representaciones en Bahia Blanca durante el siglo XX. Bahía Blanca: EdiUNS.

Cernadas, Mabel Nélida, Bracamonte, Lucía y Agesta, María de las Nieves (2016). «Bahía Blanca de la "segunda fundación" a la sociedad de masas (1880-1943)». En: Cernadas, Mabel Nélida; Bracamonte, Lucía; Agesta, María de las Nieves y Paz Trueba, Yolanda de. Escenarios de la sociabilidad en el sudoeste bonaerense durante la primera mitad del siglo XX, 15-49. Bahía Blanca: EdiUNS. 
Cernadas, Mabel Nélida y Marcilese, José (2017). "Algunas reflexiones sobre las culturas políticas en Bahía Blanca desde la sociabilidad: las sociedades de fomento en los ámbitos barriales (1928-1955)». En: Cernadas, Mabel Nélida; Agesta, María de las Nieves y López Pascual, Juliana (coords.). Amalgama y distinción. Culturas politicas y sociabilidades en Bahía Blanca, 23-66. Bahía Blanca: EdiUNS.

Cimatti, Bruno (2016a). "Fascistas y antifascistas en las elecciones de la Sociedad Italia Unita de Bahía Blanca (enero de 1927)». Avances del Cesor, 13 (14), 117-136. $<$ https://dialnet.unirioja.es/servlet/articulo? codigo $=5635570>$.

- (2016b). «La sociabilidad fascista en construcción. El fascismo y la colectividad italiana de Bahía Blanca (1926-1927)». Pasado Abierto. Revista del CEHis, 3, 6-24. <https://fh.mdp.edu.ar/revistas/index.php/pasadoabierto/article/view/1742>.

- (2017). «Una guerra, dos fascismos. Indagaciones sobre la recepción de la Guerra Ítalo-etíope en la colectividad italiana de Bahía Blanca». Altreitalie. Rivista Internazionale di Studi sulle Migrazione Italiane, 55, 76-92. <https://www.altreitalie.it/ pubblicazioni/rivista/n--55/acquista-versione-digitale/una-guerra--dos-fascismos-indagaciones-sobre-la-recepcion-de-la-guerra-italo-etiope-en-la-colectividad-italiana-de-bahia-blanca.kl>.

Devoto, Fernando (2006). Historia de los italianos en la Argentina. Buenos Aires: Editorial Biblos.

Devoto, Fernando y Míguez, Eduardo (comps.) (1992). Asociacionismo, trabajo e identidad étnica. Los italianos en América Latina en una perspectiva comparada. Buenos Aires: CEMLA-CSER-IEHS.

Devoto, Fernando y Rosoli, Gianfausto (eds.) (2000). La inmigración italiana en la Argentina. Buenos Aires: Editorial Biblos.

Diniz Filho, Luiz Lopes (1993). «O Monumento dos Bandeirantes: um estudo crítico sobre as relações entre espaço, política e cultura». Boletim Paulista de Geografia, 71, 65-82. <http://www.agb.org.br/publicacoes/index.php/boletim-paulista/article/ view/914/807>.

Dosio, Patricia Andrea (2010). «El monumento a Garibaldi en Buenos Aires (18821904)». Iberoamericana. América Latina, España, Portugal, 10 (40), 63-84. <http://dx.doi.org/10.18441/ibam.10.2010.40.63-84>

Duggan, Christopher (2017). Historia de Italia. Madrid: Akal.

Duncan, James (1989). "The power of place in Kandy, Sri Lanka: 1780-1980». En: AGnew, John y Duncan, James (eds.). The power of place: bringing together geographical and sociological imaginations, 185-201. Londres: Unwin Human.

FinCHelstein, Federico (2010). Fascismo trasatlántico. Ideología, violencia y sacralidad en Argentina y en Italia, 1919-1945. Buenos Aires: Fondo de Cultura Económica.

Fotia, Laura (2015). La politica culturale del fascismo in Argentina (1923-1940). Tesis del Dottorato di Ricerca in Scienze Politiche, Sezione: Studi Europei e Internazionali, Departamento di Scienze Politiche, Università degli Studi di Roma Tré. <http://dspace-roma3.caspur.it/bitstream/2307/5057/1/Politica\%20culturale\%20 fascismo\%20in\%20Argentina\%20Fotia.pdf>.

Gentile, Emilio (1986). «L'emigrazione italiana in Argentina nella politica di espansione del nazionalismo e del fascismo». Storia Contemporanea, 17 (3), 355-396.

- (2007). El culto del littorio: la sacralización de la política en la Italia fascista. Buenos Aires: Siglo XXI Editores.

Goebel, Michael (2014). «Italian Fascism and Diasporic Nationalisms in Argentina, Brazil, and Uruguay». En: Foote, Nicola y Goebel, Michael (eds.). Immigration 
and National Identity in Latin America, 234-255. Gainesville: The University Press of Florida.

González Calleja, Eduardo (2012). «De emigrantes a representantes de la nación en el extranjero: la política de encuadramiento partidista de los Fasci Italiani all'Estero". Pasado y Memoria. Revista de Historia Contemporánea, 11, 19-39. $<$ https://www.redalyc.org/articulo.oa?id=521552321002>.

Grillo, María Victoria (2006). "Creer en Mussolini. La proyección exterior del fascismo italiano (Argentina, 1930-1939)». Ayer, 62 (2), 231-256. <http://www.jstor. org/stable/41324978>.

Halperín Donghi, Tulio (2005). Historia contemporánea de América Latina. Madrid: Alianza Editorial.

Hartmann, Ivar (2002). Aspectos da Guerra dos Farrapos. Nova Hamburgo: Editora Feevale.

Harvey, David (1979). "Monument and Myth». Annals of the Association of American Geographers, 69 (3), 362-381. <https://www.jstor.org/stable/2562969>.

Hay, Iain; Hughes, Andrew y Tutton, Mark (2004). «Monuments, Memory and Marginalisation in Adelaide's Prince Henry Gardens». Geografiska Annaler, 86 (B/3), 201-21.

<http://dx.doi.org/10.1111/j.0435-3684.2004.00162.x>

Hershrovitz, Linda (1993). "Tiananmen Square and the Politics of Place». Political Geography, 12, 395-420. <http://dx.doi.org/ 10.1016/0962-6298(93)90010-5>

Hовsваwм, Eric (1990). Nations and Nationalism since 1780: Programme, Myth, Reality. Cambridge: Cambridge University Press.

Hobsbawm, Eric y Ranger, Terence (eds.) (1983). The Invention of Tradition. Cambridge: Cambridge University Press.

Johnson, Nuala (1994). "Sculpting Heroic Histories: Celebrating the Centenary of the 1798 Rebellion in Ireland». Transactions of the Institute of British Geographers, 19 (1), 78-93. <https://doi.org/10.2307/622447>

- (1995). "Cast in Stone: Monuments, Geography, and Nationalism». Environment and Planning D: Society and Space, 13, 51-65. <http://dx.doi.org/ 10.1068/d130051>

Lobato CorrêA, Roberto (2005). "Monumentos, politica e espaço». Scripta Nova. Revista Electrónica de Geografía y Ciencias Sociales, 9 (183), s/p.

- (2011). «Las formas simbólicas espaciales y la política». En: Zusman, Perla; HaesBaert, Rogério; Castro, Hortensia y Adamo, Susana (eds.). Geografías culturales. Aproximaciones, intersecciones y desafíos, 21-48. Buenos Aires: EFFL.

López de Pagani, Clelia, Avale de Iurman, Nora y Gillio, Nora di (1971). Contribución al estudio del impacto inmigratorio en el sudoeste de la provincia de Buenos Aires: la inmigración italiana, 1880-1914. Bahía Blanca: Universidad Nacional del Sur.

Lyttleton, Adrian (2012). "The Hero and the People». En: Patriarca, Silvina y Riall, Lucy (eds.). The Risorgimento Revisited. Nationalism and Culture in Nineteenth Century Italy, 37-55. Basingstoke: Palgrave Macmillan.

Massey, Doreen (2009). "Concepts of space and power in theory and in political practice». Documents d'Anàlisi Geogràfica, 55, 15-26.

Milza, Pierre (1983). "Le fascisme italien à Paris». Revue d'Histoire Moderne et Contemporaine, 30, 420-452.

<https://doi.org/10.3406/rhmc.1983.1246> 
Monacci, Gustavo (1988). «Inmigración». En: Weinberg, Félix (dir.). Historia del sudoeste bonaerense, 205-243. Buenos Aires: Plus Ultra.

Moraes, Antonio Carlos Robert (1988). Ideologias Geográficas. Espaço, Cultura e Política no Brasil. São Paulo: Hucitec.

Newton, Ronald (1994). «Ducini, Promienti, Antifascisti: Italian Fascism and the Italo-Argentine Collectivity, 1922-1945». The Americas, 51 (1), 41-66. $<$ https://doi.org/10.2307/1008355>

Nora, Pierre (2008). Pierre Nora en Les lieux de mémoire. Montevideo: Ediciones Trilce.

Osborne, Brian (1998). «Constructing landscapes of power: the George Etienne Cartier monument, Montreal». Journal of Historical Geography, 24 (4), 431-458. <http://dx.doi.org/10.1006/jhge.1998.0090>

Prislei, Leticia (2008). Los orígenes del fascismo argentino. Buenos Aires: Edhasa.

Ribas, Diana y Tolcachier, Fabiana (2012). La California del Sur: de la construcción del nudo ferro-portuario al centenario local (Bahía Blanca, 1884-1928). Bahía Blanca: EdiUNS.

Rosanvallon, Pierre (2003). Por una historia conceptual de lo político. Buenos Aires: Fondo de Cultura Económica.

Rowntree, Lester y Conkey, Margaret (1980). «Symbolism and the Cultural Landscape». Annals of the Association of American Geographers, 70 (4), 459-474. <https://doi.org/10.1111/j.1467-8306.1980.tb01327.x>

Scarzanella, Eugenia (comp.) (2007). Fascistas en América del Sur. Buenos Aires: Fondo de Cultura Económica.

Sergi, Pantaleone (2012). Patria di carta. Storia di un quotidiano coloniale e del giornalismo italiano in Argentina. Cosenza: Luigi Pellegrini Editore.

Soriano, Fabrizio (2010). «Il mito garibaldino nell'orbita del Fascismo». Cercles. Revista d'Història Cultural, 13, 95-106. <http://dx.doi.org/10.1344/\%25x>

Vagliente, Pablo (2016). Asociativa, movilizada, violenta. La vida pública en Córdoba, 1850-1930. Villa María: Eduvim.

VeCCHI, Rodrigo (2003). «De escuadras, compases y camisas negras: el monumento a Giuseppe Garibaldi o la representación formal de los conflictos en la colectividad italiana bahiense (1927-1928)». II Congreso Internacional de Teoría e Historia de las Artes y X Jornadas CAIA, Buenos Aires, del 10 al 13 de septiembre.

VelázQuez Ramírez, Adrián (2013). «La producción política del espacio: el problema de la praxis». Utopía y praxis latinoamericana, 18 (63), 63-74. <http://www.redalyc. org/articulo.oa?id=27937086006>.

Weinberg, Félix y Buffa de Bottaro, Norma (1982). «El aporte inmigratorio en la conformación de las clases medias de la ciudad de Bahía Blanca». Cuadernos del Sur, 15, 79-97.

Whelan, Yvonne (2002). «The construction and destruction of a colonial landscape: monuments to British monarchs in Dublin before and after independence». Journal of Historical Geography, 28 (4), 508-533. <https://doi.org/10.1006/jhge.2002.0441>

ZanatTa, Loris (2003). "I Fasci in Argentina negli anni Trenta». En: Franzina, Emilio y SANFILIPpo, Matteo (comps.). Il fascismo e gli emigrati. La parabola dei fasci italiani all'estero (1920-1943), 140-151. Roma-Bari: Editori Laterza. 
